\title{
Treatment of COPD Exacerbation in Switzerland: Results and Recommendations of the European COPD Audit
}

\author{
Michael Buess $^{a} \quad$ Daniel Schilter ${ }^{b}$ Tino Schneider ${ }^{c}$ Marc Maurer ${ }^{d}$ \\ Heinz Borer ${ }^{\mathrm{e}}$ Robert Thurnheer ${ }^{f}$ Erich Köhlerg Lilian Junker ${ }^{\mathrm{h}}$ Kathleen Jahn ${ }^{\mathrm{a}}$ \\ Michael Grob ${ }^{i}$ Jochen Rüdiger ${ }^{a}$ Thomas Geiser ${ }^{j} \quad$ Erich Helfenstein ${ }^{k}$ \\ Markus Solèrl René Fiechter ${ }^{\mathrm{m}}$ Thomas Sigrist ${ }^{\mathrm{n}}$ Patrick Brun ${ }^{\circ}$ \\ Jürg Barandun $^{p} \quad$ Eva Koltai $^{q} \quad$ José Luis López-Campos ${ }^{r}$ Sylvia Hartl ${ }^{\mathrm{s}}$ \\ Michael Roberts ${ }^{t}$ Desiree M. Schumann ${ }^{a}$ Michael Tamm ${ }^{a}$ Daiana Stolz ${ }^{a}$ \\ ${ }^{a}$ Clinic of Respiratory Medicine, University Hospital Basel, Basel, ${ }^{b}$ Spital Lindenhof, Bern, ${ }^{C}$ Kantonsspital St. Gallen, \\ St. Gallen, ${ }^{d}$ Kantonsspital Olten, Olten, ${ }^{e}$ Bürgerspital Solothurn, Solothurn, ${ }^{f}$ Spital Thurgau, Münsterlingen,

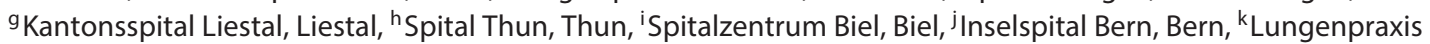 \\ Hirslanden - Klinik St. Anna, Luzern, 'St. Claraspital, Basel, ${ }^{m}$ GZO Spital Wetzikon, Wetzikon, ${ }^{n}$ Klinik Barmelweid, \\ Barmelweid, ${ }^{\circ}$ Berner Reha Zentrum, Bern, ${ }^{\mathrm{P}}$ Lungenzentrum Hirslanden, Zurich, and ${ }^{9}$ Gesundheitszentrum Fricktal, \\ Laufenburg, Switzerland; ' ${ }^{2}$ ospital Universitario Virgen del Rocío, Instituto de Biomedicina de Sevilla (IBiS), Sevilla, \\ Spain; ${ }^{5}$ Ludwig Boltzmann Institute of COPD and Respiratory Care, Department of Respiratory and Critical Care, \\ Otto Wagner Hospital, Vienna, Austria; ${ }^{\mathrm{t} I n s t i t u t e}$ of Health Sciences Education, Barts and The London School of \\ Medicine and Dentistry, Queen Mary University of London, London, UK
}

\section{Keywords}

Chronic obstructive pulmonary disease $\cdot$ Switzerland .

Exacerbation · GOLD · ERS · Europe · Audit · Therapy ·

Bundle $\cdot$ Recommendations

\begin{abstract}
Background: The European COPD Audit initiated by the European Respiratory Society (ERS) evaluated the management of hospital admissions due to exacerbation of chronic obstructive pulmonary disease (COPD) in several European countries. Data on the treatment of severe acute exacerbations of COPD (AECOPDs) in Switzerland are scarce. Objectives: In light of the GOLD 2010 guidelines, this work aims
\end{abstract}

\section{KARGER}

(C) 2017 S. Karger AG, Basel

E-Mail karger@karger.com

www.karger.com/res to examine the quality of care for AECOPD and to provide specific recommendations for the management of severe AECOPD in Switzerland. Methods: A total of 295 patients requiring hospital admission to 19 Swiss hospitals due to exacerbation of COPD during a predefined 60 days in 2011 were included in the study. We compared the Swiss data to the official GOLD 2010 recommendations and to the results of the other European countries. Results: Approximately $43 \%$ of the Swiss patients with severe AECOPD were current smokers at hospital admission, compared to 33\% of the patients in other European countries $(p<0.001)$. In Switzerland and in Europe, spirometry data were not available for most patients at hospital admission (65 and 60\%, respectively; $p=0.08$ ). In comparison to other European countries, anti-

Prof. Daiana Stolz, MD, MPH

Clinic of Pulmonary Medicine and Respiratory Cell Research University Hospital Basel, Petersgraben 4

CH-4031 Basel (Switzerland)

E-Mail daiana.stolz@ usb.ch 
biotics were prescribed $14 \%$ less often in Switzerland ( $p<$ 0.001 ). Only $79 \%$ of the patients in the Swiss cohort received treatment with a short-acting bronchodilator at admission. Conclusions: Considering the overall high standard of health care in Switzerland, in light of the GOLD 2010 guidelines we are able to make 7 recommendations to improve and standardize the management of severe AECOPD for patients treated in Switzerland.

(c) 2017 S. Karger AG, Basel

\section{Introduction}

Chronic obstructive pulmonary disease (COPD) remains associated with high morbidity and mortality. According to the World Health Organisation (WHO), in 2020 COPD will rank fifth worldwide in burden of disease. Furthermore, it is a leading cause of death and expected to become the seventh leading cause of disabilityadjusted life years lost [1, 2]. In Switzerland, around 200,000-300,000 patients suffer from COPD of GOLD (Global Initiative for Chronic Obstructive Lung Disease) stage II or higher [3].

Many COPD patients experience exacerbations of the disease. The GOLD defines COPD exacerbation as "an acute event characterized by a worsening of the patient's respiratory symptoms that is beyond normal day-to-day variations and leads to change of the medication" [4]. The clinical presentation for exacerbations of COPD is heterogeneous and can be triggered by infectious and noninfectious conditions. Determining the cause of the exacerbation is challenging, and thus far there are no tools capable of diagnosing or predicting the duration of an acute exacerbation of COPD (AECOPD) [5]. AECOPDs requiring hospital admission are considered to be severe and are associated with increased mortality [6] as well as with an increased mortality risk of $30-43 \%$ within the 12 months following the AECOPD [6-8]. There is a direct correlation between the number of severe AECOPDs and the mortality rate among hospitalized patients with COPD [9]. The administration of noninvasive ventilation (NIV) to hypercapnic patients decreases the mortality rate by $21 \%$ [10], which strongly suggests that in-hospital management directly influences the prognosis of patients with severe AECOPD. Therefore, it is of paramount importance to provide adequate and comprehensive treatment to this severely affected patient population.

The European COPD Audit initiated by the European Respiratory Society (ERS) in collaboration with the Forum of European Respiratory Societies (FERS) aimed to monitor the management of severe AECOPD in 13 European countries (Austria, Belgium, Croatia, Greece, Malta, Poland, Ireland, Romania, Slovakia, Spain, Switzerland, Turkey, and the UK) [11-13]. In Switzerland, patients were recruited from 19 hospitals distributed throughout 13 Swiss cantons.

Data on the management of AECOPD in Switzerland are scarce. Thus, the aim of this study was to examine the quality of care for AECOPD in Swiss hospitals in light of the GOLD 2010 guidelines and to provide specific recommendations for the management of severe AECOPD in Switzerland.

\section{Materials and Methods}

The study was classified as a quality control study by the Ethics Committee of Basel (307/10), and as such, no patient consent was required.

The full methodology of the study has been reported [12]. Patients requiring hospital admission due to AECOPD during a predefined 2-month period in 2011 at 19 Swiss hospitals (Kantonsspital Aarau, Universitätsspital Basel, St. Claraspital Basel, Spital Bern-Tiefenau, Inselspital Bern, Kantonsspital Chur, Kantonsspital Liestal, Kantonsspital Bruderholz, Spitalzentrum Biel, Spital Laufenburg, Lungenpraxis Hirslanden - Klinik St. Anna Luzern, Luzerner Höhenklinik Montana, Zuger Kantonsspital, Bürgerspital Solothurn, Kantonsspital St. Gallen, Spital Thun, Kantonsspital Münsterlingen, GZO Spital Wetzikon, and Lungenzentrum Hirslanden Zürich) were considered eligible for the study. The inclusion and exclusion criteria have been reported previously [12]. In short, patients who were admitted to the hospital for $\geq 12 \mathrm{~h}$ with a senior clinician-made diagnosis of COPD exacerbation or any other synonym, confirmed at discharge by the investigator/audit lead, and patients who were admitted to the hospital for $\geq 12 \mathrm{~h}$ with a respiratory cause of admission as indicated by the discharge report and a history compatible with COPD were included in the study. Most of the Swiss hospitals from which patients were recruited were located in the German-speaking areas of Switzerland. The hospital catchment population was 3,524,177 citizens [12].

The cases were examined by a respiratory specialist in charge of the emergency ward. When an exacerbation was identified, detailed demographic and medical history data were collected and entered into a Web-based application. Data collection and imputation were standardized and centrally managed by a trained professional. The follow-up period was 90 days. Figure 1 depicts the flowchart for patient inclusion in the study.

The following GOLD recommendations were investigated according to the European COPD Audit Study data: (1) symptoms; (2) arterial blood gas results; (3) chest radiograph results; (4) medical treatment; (5) oxygen therapy; and (6) type of mechanical ventilation [12].

\section{Statistical Analysis}

Differences in dichotomous variables were evaluated using the $\chi^{2}$ test or Fisher's exact test, as appropriate. Normally distributed parameters were analyzed using the Student $t$ test for equality of
356

Respiration 2017;94:355-365 DOI: $10.1159 / 000477911$
Buess et al. 


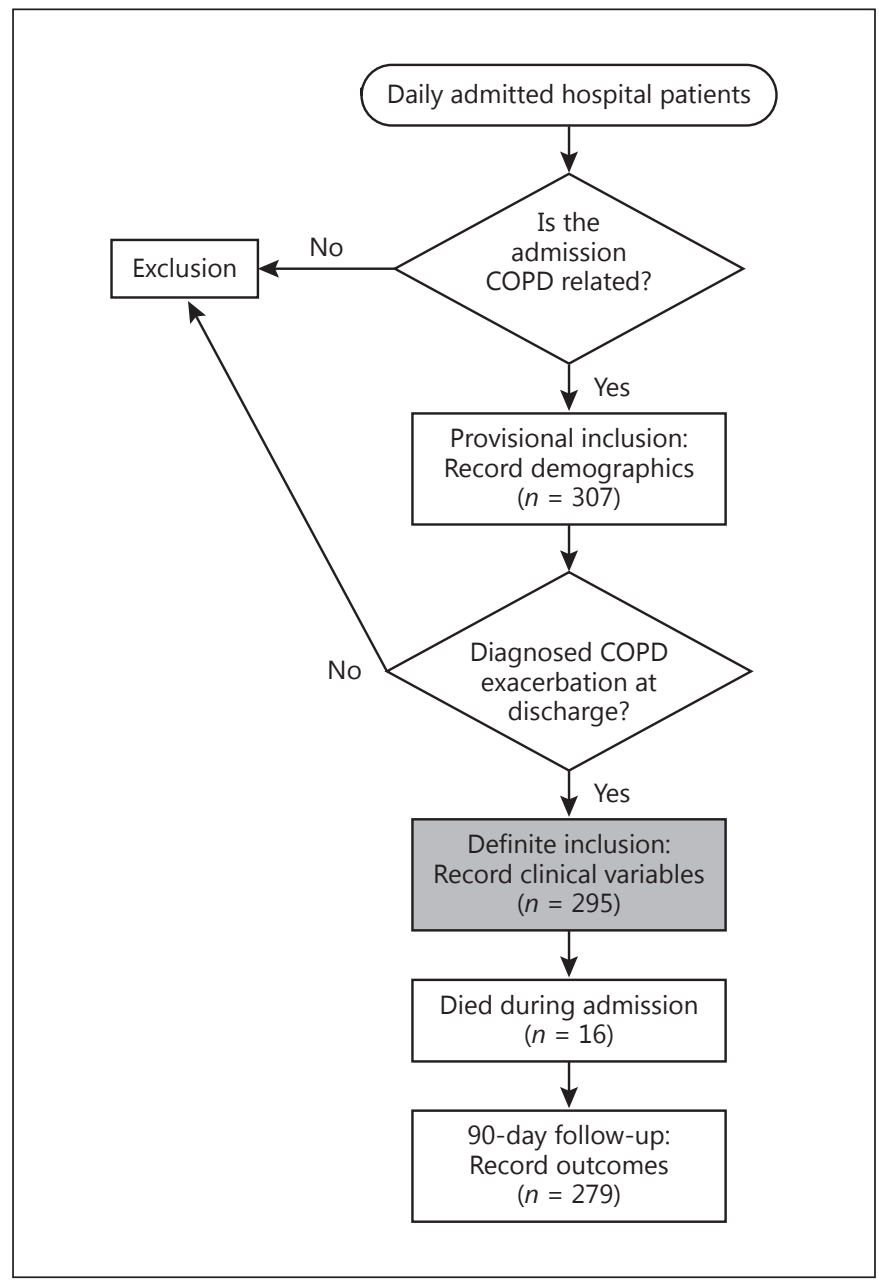

Fig. 1. Flowchart depicting patient inclusion. COPD, chronic obstructive pulmonary disease.

means. All other continuously nonnormally distributed parameters were evaluated using the nonparametric Mann-Whitney U test or the Kruskal-Wallis test, as appropriate.

The Statistical Package for the Social Sciences (SSPS Inc., version 19 and 23 for Windows) was used. All tests were two-tailed; a $p$ value of $<0.05$ was considered significant. The results are expressed as mean (standard deviation) or median and interquartile range, unless otherwise stated.

\section{Results}

\section{Patient Characteristics}

A total of 307 Swiss patients were included in the database, and the data on 295 patients were analyzed (Fig. 1). Six of the discharged patients had been misdiagnosed, 1 died, 1 left within the first $12 \mathrm{~h}$ of hospitalization, 3 were

Treatment of COPD Exacerbation in Switzerland moved to a nonparticipating hospital, and 1 had an incorrect admission date. The other European countries included 15,723 patients. The patient characteristics for Switzerland and the other European countries are presented in Table 1.

In the Swiss cohort, there were 165 (55.9\%) male patients, the mean age was 70.7 years (SD 12), the average body mass index was 25 (SD 6.5), and the mean forced expiratory volume in $1 \mathrm{~s}\left(\mathrm{FEV}_{1}\right)$ was $44.8 \%$ predicted (SD 19). A total of $43.1 \%(122 / 283)$ of the Swiss patients with an AECOPD were classified as smokers at hospital admission, in contrast to $32.8 \%(4,890 / 14,898)$ in the other European countries $(p<0.001)$. The main symptoms in both the Swiss cohort and the cohorts of the other European countries were increased dyspnea (92.5 vs. $97.1 \%$; $p<$ 0.001 ) and increased sputum volume (49.3 vs. $68.9 \%$; $p<$ $0.001)$. Most of the patients requiring hospitalization for AECOPD suffered from GOLD stage III COPD (50.7\% in Switzerland vs. $45.5 \%$ in Europe; $p=0.391$ ).

The most frequent comorbidities are shown in Figure 2. Congestive heart failure $(p<0.001)$, metastatic solid malignancy $(p<0.001)$, dementia $(p<0.001)$, and renal disease $(p<0.001)$ were significantly more common in the Swiss patients than in the patients from the other European countries. Conversely, myocardial infarction $(p<$ $0.001)$, cerebrovascular disease $(p=0.006)$, and ulcer disease $(p=0.011)$ were more common in the other European countries than in Switzerland.

\section{Organization and Resources}

The organization and resources of the hospitals caring for AECOPD patients in Switzerland and in other countries of Europe are depicted in Table 2. The resources of the Swiss hospitals were superior or equivalent to those of the other European hospitals in several categories (Table 2). NIV was available in $100 \%$ of the participating Swiss hospitals compared to $86.9 \%$ of the hospitals in the other European countries ( $p=0.417$ ). In $94.7 \%$ of the Swiss hospitals, a high dependency unit was available, compared to $47.1 \%$ of the hospitals in the other European countries $(p=0.001)$. In Switzerland, patients have access to a pulmonary rehabilitation program in $89.5 \%$ of the participating hospitals, compared to $48.1 \%$ of the participating hospitals in the other European countries $(p=0.004)$. There were also significant differences in the types of rehabilitation program offered, with home-based therapy being the most prominent program offered in Switzerland compared to the other European countries (68.4 vs. 4.8\%). A hospitalbased program was the main therapy in the other European countries compared to Switzerland (17.7 vs. $5.3 \%$ ).

Respiration 2017;94:355-365 357 
Table 1. Patient characteristics

\begin{tabular}{|c|c|c|c|c|c|}
\hline \multirow[t]{2}{*}{ Characteristics } & \multicolumn{2}{|l|}{ Switzerland } & \multicolumn{2}{|l|}{ Europe } & \multirow[t]{2}{*}{$p$} \\
\hline & $\begin{array}{l}n \text { or mean } \\
(\% \text { or SD) }\end{array}$ & patients, $n$ & $\begin{array}{l}n \text { or mean } \\
(\% \text { or SD) }\end{array}$ & patients, $n$ & \\
\hline Total patients & $100 \%$ & 295 & $98.2 \%$ & 15,723 & 0.068 \\
\hline Age, years & $70.7(12.1)$ & 295 & $70.8(10.7)$ & 15,721 & 0.915 \\
\hline Male gender & 165 (55.9) & 295 & $10,700(68.1)$ & 15,723 & $<0.001$ \\
\hline Height, cm & $166.8(8.0)$ & 251 & $165.7(9.0)$ & 9,307 & 0.046 \\
\hline Weight, kg & $70.1(18.6)$ & 274 & $73.2(18.8)$ & 9,449 & 0.007 \\
\hline BMI & $25.0(6.5)$ & 250 & $26.7(6.4)$ & 9,139 & $<0.001$ \\
\hline \multicolumn{6}{|l|}{ Smoking status } \\
\hline Smoker & $122(43.1)$ & 283 & $4,890(32.8)$ & 14,898 & $<0.001$ \\
\hline Ex-smoker & $138(48.8)$ & 283 & $9,179(61.6)$ & 14,898 & $<0.001$ \\
\hline Never-smoker & $23(8.3)$ & 283 & $829(5.6)$ & 14,898 & 0.085 \\
\hline Pack-years & $54.9(24.3)$ & 109 & $53.2(28)$ & 3,777 & 0.538 \\
\hline \multicolumn{6}{|l|}{ Symptoms } \\
\hline Dyspnea increased & $273(92.5)$ & 295 & $15,136(97.1)$ & 15,584 & $<0.001$ \\
\hline Sputum increased & $145(49.3)$ & 294 & $10,228(68.9)$ & 14,834 & $<0.001$ \\
\hline Sputum color change & $109(37.8)$ & 288 & $8,025(56.0)$ & 14,332 & $<0.001$ \\
\hline \multicolumn{6}{|l|}{$A B G A$} \\
\hline Taken & $238(85.6)$ & 278 & $12,953(84.1)$ & 15,397 & $<0.001$ \\
\hline $\mathrm{pH}$ & $7.40(0.078)$ & 233 & $7.40(0.074)$ & 12,808 & 0.813 \\
\hline $\mathrm{HCO}_{3}, \mathrm{mmol} / \mathrm{L}$ & $26.5(4.7)$ & 228 & $28.1(5.2)$ & 12,207 & $<0.001$ \\
\hline $\mathrm{pO}_{2}, \mathrm{kPa}$ & $9.4(4.9)$ & 237 & $8.6(3.4)$ & 12,826 & 0.015 \\
\hline $\mathrm{pCO}_{2}, \mathrm{kPa}$ & $6.1(2.1)$ & 236 & $6.4(2.2)$ & 12,833 & 0.033 \\
\hline \multicolumn{6}{|l|}{ Spirometry } \\
\hline FVC, \% predicted & $69.6(21.4)$ & 144 & $65.4(20.4)$ & 8,863 & 0.014 \\
\hline $\mathrm{FEV}_{1}, \%$ predicted & $44.8(19.0)$ & 186 & $44.0(17.4)$ & 9,089 & 0.573 \\
\hline $\mathrm{FEV}_{1} / \mathrm{FVC}, \%$ predicted & $58.0(16.7)$ & 148 & $53.6(15.3)$ & 9,064 & 0.002 \\
\hline \multicolumn{6}{|l|}{$X$-ray result } \\
\hline Normal & $59(20)$ & 295 & $3,496(22.3)$ & 15,700 & 0.0181 \\
\hline Bronchiectasis & $5(1.7)$ & 295 & $867(5.5)$ & 15,700 & 0.007 \\
\hline Hyperinflation & $76(25.8)$ & 295 & $5,331(34.0)$ & 15,700 & 0.007 \\
\hline Consolidation & $71(24.1)$ & 295 & $2,898(18.5)$ & 15,700 & 0.013 \\
\hline Pleural effusion & $29(9.8)$ & 295 & $426(2.7)$ & 15,700 & $<0.001$ \\
\hline Lung cancer & $5(1.7)$ & 295 & $394(2.5)$ & 15,700 & 0.175 \\
\hline \multicolumn{6}{|l|}{ GOLD stage } \\
\hline 1 & $5(3.4)$ & 148 & $190(2.4)$ & 8,057 & 0.45 \\
\hline 2 & $31(20.9)$ & 148 & $2,144(26.5)$ & 8,057 & 0.12 \\
\hline 3 & $75(50.7)$ & 148 & $3,662(45.5)$ & 8,057 & 0.391 \\
\hline 4 & $37(25)$ & 148 & $2,061(25.6)$ & 8,057 & 0.775 \\
\hline
\end{tabular}

BMI, body mass index; ABGA, arterial blood gas analysis; FVC, forced vital capacity; $\mathrm{FEV}_{1}$, forced expiratory volume in $1 \mathrm{~s}$.

Pharmacological Treatment for COPD

before Admission, during Hospitalization,

and after Discharge

The prescribed pharmacological therapy for COPD before, during, and after hospital admission in Switzer- land and the other European countries is presented in Table 3. Differences were noted in the frequency of theophylline administration before admission (3.7 vs. 16.6\%; $p<0.001$ ), during hospitalization ( 1.0 vs. $14.5 \%$; $p<$ 0.001 ), and after discharge (3.1 vs. $20.2 \%$; $p<0.001$ ) be- 
Table 2. Organization and resources

\begin{tabular}{|c|c|c|c|c|c|}
\hline \multirow[t]{2}{*}{ Characteristics } & \multicolumn{2}{|l|}{ Switzerland } & \multicolumn{2}{|l|}{ Europe } & \multirow[b]{2}{*}{$p$} \\
\hline & $n(\%)$ & hospitals, $n$ & $n(\%)$ & hospitals, $n$ & \\
\hline ICU available & $17(89.5)$ & 19 & $370(91.4)$ & 405 & 0.928 \\
\hline Spirometry available & $18(94.7)$ & 19 & $400(98.8)$ & 405 & 0.471 \\
\hline Respiratory physician on call every day & $15(78.9)$ & 19 & $195(48.1)$ & 405 & 0.061 \\
\hline Respiratory ward available & $13(68.4)$ & 19 & $332(82.0)$ & 405 & 0.455 \\
\hline Respiratory team available & $17(89.5)$ & 19 & $363(89.6)$ & 405 & 0.945 \\
\hline Respiratory outpatient clinic available & $18(94.7)$ & 19 & $362(89.8)$ & 403 & 0.808 \\
\hline Respiratory outpatient clinic for COPD & $13(68.4)$ & 19 & $248(61.5)$ & 403 & 0.717 \\
\hline Respiratory specialists available* & $3.0(2.1)$ & 19 & $6.5(6.9)$ & 403 & $<0.001$ \\
\hline Respiratory physiotherapists available* & $5.8(6.7)$ & 19 & $1.9(2.1)$ & 403 & 0.02 \\
\hline Specialty triage for COPD operated & $6(31.6)$ & 19 & $129(32.0)$ & 403 & 0.925 \\
\hline High dependency unit available* & $18(94.7)$ & 19 & $190(47.1)$ & 403 & 0.001 \\
\hline Seen by physiotherapists* & $79.2(25.8)$ & 12 & $52.3(40.7)$ & 336 & 0.004 \\
\hline Seen by a respiratory specialist & $67.1(30.7)$ & 17 & $69.5(33.7)$ & 371 & 0.772 \\
\hline NIV available & $19(100)$ & 19 & $359(89.1)$ & 403 & 0.417 \\
\hline Invasive mechanical ventilation available & $17(89.5)$ & 19 & $303(75.2)$ & 403 & 0.469 \\
\hline Pulmonary rehabilitation program available* & $17(89.5)$ & 19 & $194(48.1)$ & 403 & 0.004 \\
\hline Hospital-based pulmonary rehabilitation* & $1(5.3)$ & 19 & $70(17.7)$ & 395 & $<0.001$ \\
\hline Home-based pulmonary rehabilitation* & $13(68.4)$ & 19 & $19(4.8)$ & 395 & $<0.001$ \\
\hline Early discharge program available & $7(36.8)$ & 19 & $128(31.8)$ & 403 & 0.875 \\
\hline Palliative care available & $8(42.1)$ & 19 & $244(60.5)$ & 403 & 0.377 \\
\hline Long-term oxygen program available & $18(94.7)$ & 19 & $351(87.1)$ & 403 & 0.692 \\
\hline
\end{tabular}

ICU, intensive care unit; COPD, chronic obstructive pulmonary disease; NIV, noninvasive ventilation. * Significant.

Fig. 2. The most frequent comorbidities with chronic obstructive pulmonary disease exacerbation.

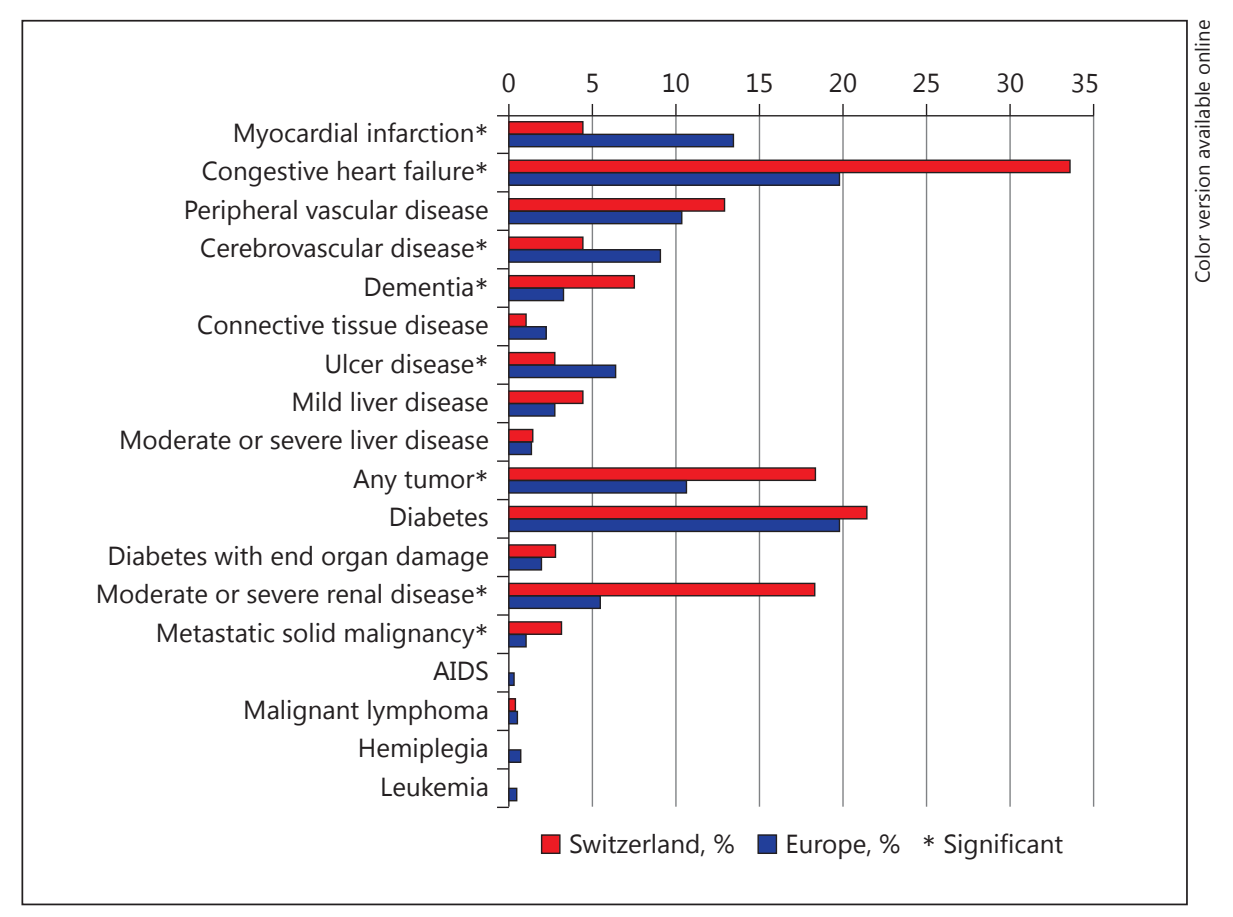

Treatment of COPD Exacerbation in Switzerland
Respiration 2017;94:355-365 DOI: $10.1159 / 000477911$ 
Table 3. Pharmacological treatment before and during hospital admission and after discharge

\begin{tabular}{|c|c|c|c|c|c|c|c|c|c|}
\hline Treatment & $\begin{array}{l}\text { Switzerland } \\
\text { before }\end{array}$ & $\begin{array}{l}\text { Europe } \\
\text { before }\end{array}$ & $p$ & $\begin{array}{l}\text { Switzerland } \\
\text { during }\end{array}$ & $\begin{array}{l}\text { Europe } \\
\text { during }\end{array}$ & $p$ & $\begin{array}{l}\text { Switzerland } \\
\text { after }\end{array}$ & $\begin{array}{l}\text { Europe } \\
\text { after }\end{array}$ & $p$ \\
\hline $\mathrm{LABA}+\mathrm{ICS}$ & $157(53.2)$ & $9,027(57.4)$ & 0.149 & & & & $169(57.3)$ & $10,990(69.9)$ & $<0.001$ \\
\hline LABA & $23(7.8)$ & $1,459(9.3)$ & 0.384 & & & & $29(9.8)$ & $1,530(9.7)$ & 0.954 \\
\hline LAMA & $132(44.7)$ & $7,319(46.5)$ & 0.538 & & & & $166(56) 3$. & $9,428(60)$ & 0.2 \\
\hline Oral theophylline & $11(3.7)$ & $2,606(16.6)$ & $<0.001$ & & & & $9(3.1)$ & $3,170(20.2)$ & $<0.001$ \\
\hline IV theophylline & & & & $3(1)$ & $2,273(14.5)$ & $<0.001$ & & & \\
\hline SABA & $102(34.6)$ & $9,483(60.3)$ & $<0.001$ & $233(79)$ & $13,322(84.7)$ & 0.007 & $115(39.0)$ & $8,948(56.9)$ & $<0.001$ \\
\hline SAMA & $80(27.1)$ & $4,202(26.7)$ & 0.88 & $221(74.9)$ & $12,185(77.5)$ & 0.293 & $95(32.2)$ & $3,861(24.6)$ & 0.003 \\
\hline \multicolumn{10}{|l|}{ Systemic } \\
\hline corticosteroids & $78(26.4)$ & $2,907(18.5)$ & 0.001 & $227(76.9)$ & $12,960(82.4)$ & 0.015 & $129(43.7)$ & $8,103(51.5)$ & 0.008 \\
\hline ICS & $32(10.8)$ & $1,949(12.4)$ & 0.424 & $46(15.6)$ & $5,394(34.1)$ & $<0.001$ & $30(10.2)$ & $1,856(11.8)$ & 0.388 \\
\hline Antibiotics & $54(18.3)$ & $3,148(20)$ & 0.465 & $214(72.5)$ & $13,559(86.2)$ & $<0.001$ & $73(24.7)$ & $6,581(41.9)$ & $<0.001$ \\
\hline Oxygen & $51(17.3)$ & $3,905(24.8)$ & 0.003 & $258(93.1)$ & $13,344(86.1)$ & $<0.001$ & $85(32.9)$ & $5,173(33.9)$ & 0.76 \\
\hline Diuretics & & & & $73(24.7)$ & $4,159(26.5)$ & 0.51 & & & \\
\hline IVS & & & & $14(5.1)$ & $272(1.7)$ & $<0.001$ & & & \\
\hline NIV & $22(7.5)$ & $416(2.6)$ & $<0.001$ & $92(33.3)$ & $2,043(13.4)$ & $<0.001$ & $21(8.2)$ & $793(5.2)$ & 0.033 \\
\hline No oxygen & & & & & & & $173(67.1)$ & $10,139(66.1)$ & 0.062 \\
\hline Ambulatory oxygen & & & & & & & $3(1.2)$ & $195(1.3)$ & 0.947 \\
\hline Long-term oxygen & & & & & & & $81(31.4)$ & $4,660(30.4)$ & 0.496 \\
\hline
\end{tabular}

Values are presented as $n$ (\%). LABA, long-acting $\beta_{2}$-agonist; ICS, inhaled corticosteroids; LAMA, long-acting muscarinic antagonist (anticholinergic); SABA, short-acting $\beta_{2}$-agonist; SAMA, short-acting muscarinic antagonist; IVS, invasive ventilatory support; NIV, noninvasive ventilatory support.

Table 4. Patient outcomes

\begin{tabular}{|c|c|c|c|c|c|}
\hline & \multicolumn{2}{|l|}{ Switzerland } & \multicolumn{2}{|l|}{ Europe } & \multirow[t]{2}{*}{$p$} \\
\hline & $n$ or mean $(\%$ or SD) & patients, $n$ & $n$ or mean $(\%$ or $\mathrm{SD})$ & patients, $n$ & \\
\hline Length of stay, days* & $11.3(8.9)$ & 294 & $8.7(8.3)$ & 15,687 & $<0.001$ \\
\hline Readmission within 90 days $^{*}$ & $71(25.4)$ & 279 & $5,278(35.3)$ & 14,949 & 0.003 \\
\hline Mortality during admission & $16(5.4)$ & 295 & $774(4.9)$ & 15,723 & 0.694 \\
\hline Follow-up mortality ${ }^{*}$ & $8(2.9)$ & 279 & $934(6.2)$ & 14,949 & 0.028 \\
\hline Overall mortality & $24(8.1)$ & 295 & $1,708(10.9)$ & 15,723 & 0.135 \\
\hline
\end{tabular}

* Significant, $p<0.05$.

tween Switzerland and the other European countries. There were also significant differences in the administration of short-acting $\beta_{2}$-agonists before admission (34.6 vs. $60.3 \%$; $p<0.001$ ), during hospitalization (79.0 vs. $84.7 \%$; $p=0.007$ ), and after discharge (39 vs. $56.9 \% ; p<0.001$ ) between Switzerland and the other European countries. Administration of systemic corticosteroids was significantly higher before admission (26.4 vs. $18.5 \%$; $p=0.001$ ) in Switzerland than in the other European countries, but it became higher during hospitalization (82.4 vs. $76.9 \%$; $p=0.015)$ and after discharge (51.5 vs. $43.7 \% ; p=0.008)$ in the other European countries than in Switzerland ( $\mathrm{Ta}-$ ble 3). In Switzerland, NIV support before admission (7.5 vs. $2.6 \%$; $p<0.001$ ), during hospitalization (33.3 vs. $13.4 \%$; $p<0.001)$, and after discharge ( 8.2 vs. $5.2 \% ; p=0.033$ ) was significantly higher than in the other European countries. At discharge, Swiss physicians less commonly prescribed the combination LABA/ICS (57.3 vs. $69.9 \%$; $p<0.001$ ) and antibiotics (24.7 vs. $41.9 \% ; p<0.001)$ as compared to the other European physicians. 
Fig. 3. Implementation of GOLD recommendations for the treatment of acute exacerbation of chronic obstructive pulmonary disease in Switzerland in comparison with other countries in Europe.

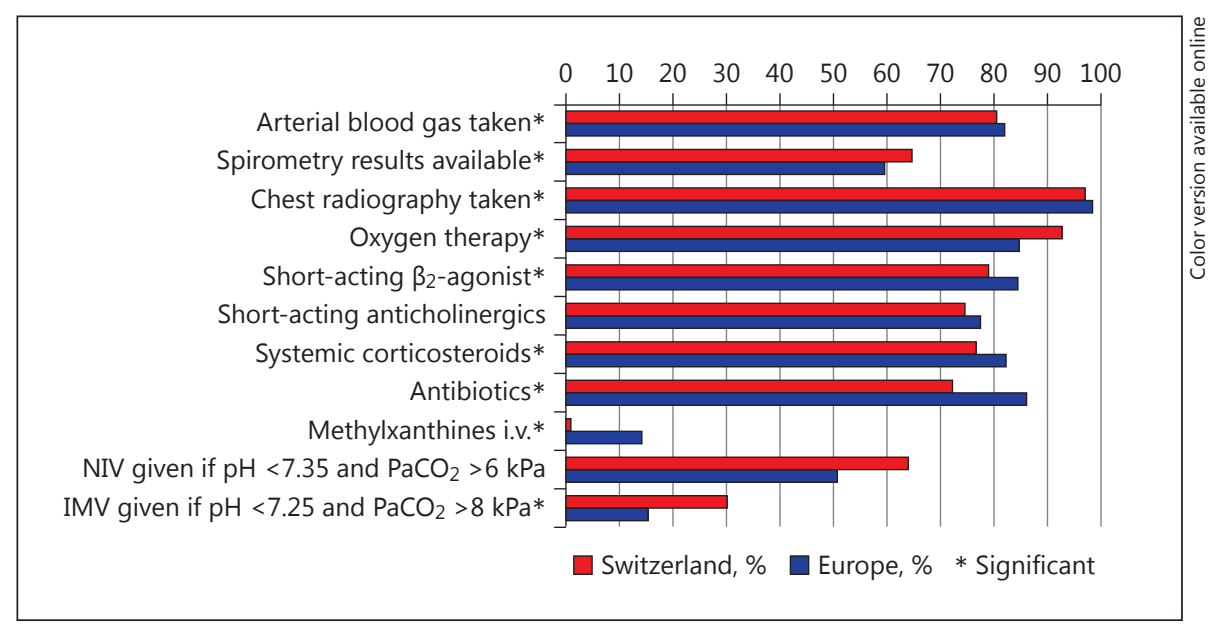

Implementation of the GOLD Recommendations for

the Treatment of COPD Exacerbations

The implementation of the GOLD recommendations for AECOPD treatment in Switzerland and in other European countries is presented in Figure 3.

1 Arterial blood gas ( $A B G$ ) should be taken to assess the severity of the exacerbation. In $85.6 \%(238 / 278)$ of all admissions in Switzerland, an arterial blood gas analysis had been performed, compared to $84.1 \%$ $(12,953 / 15,397)$ in the other European countries. The average partial oxygen pressure $\left(\mathrm{PaO}_{2}\right)$ was $9.4 \mathrm{kPa}$ and the $\mathrm{PaCO}_{2}$ was $6.1 \mathrm{kPa}$ in Switzerland, compared to $8.6 \mathrm{kPa}$ and $6.4 \mathrm{kPa}$, respectively, in the other European countries.

2 Spirometry results should be available on admission. $64.0 \%(185 / 289)$ of the patients had spirometry results available at hospital admission in Switzerland, compared to $59.1 \%(9,246 / 15,654)$ of the patients in the other European countries ( $p=0.057) .12 .8 \%(37 / 289)$ of the Swiss patients and $7.6 \%(1,189 / 15,654)$ of the patients from the other European countries had a nonobstructive $\mathrm{FEV}_{1} / \mathrm{FVC}>70 \%$ and were treated for exacerbation $(p=0.001)$.

3 Oxygen therapy should be offered on admission. In Switzerland, 93.1\% (258/277) of the patients received oxygen therapy on admission, compared to $86.1 \%$ $(13,344 / 15,492)$ of the patients in the other European countries $(p<0.001) .94 \%$ of the Swiss patients had a $\mathrm{pO}_{2}<8 \mathrm{kPa}$. Although there was no reported arterial blood sample taken, $7.2 \%(20 / 277)$ of these patients received oxygen.

4 Chest radiography should be performed at admission. In Switzerland, chest radiography was performed in

Treatment of COPD Exacerbation in Switzerland
97.3\% (287/295) of all cases. In 26.5\% (76/287) of these, hyperinflation was diagnosed, and in $1.7 \%$ $(5 / 287)$ the chest X-ray revealed lung cancer; $20.6 \%$ $(59 / 287)$ of the patients had a normal chest X-ray result and $24.7 \%(71 / 287)$ had consolidation. The results were similar in the other European countries (Table 1).

5 Short-acting $\beta_{2}$-agonists should be used. A total of $79 \%$ $(233 / 295)$ of the patients were treated with a short-acting $\beta_{2}$-agonist during hospitalization in Switzerland, as compared to $84.7 \%(13,322 / 15,723)$ patients in the other European countries $(p=0.007)$.

6 Short-acting anticholinergics can be used as an addition to short-acting $\beta_{2}$-agonists. $74.9 \%(221 / 295)$ of the patients were treated with short-acting anticholinergics during their hospitalization in Switzerland, as compared to $77.5 \%(12,185 / 17,723)$ of the patients in the other European countries $(p=0.293)$.

7 Inhaled or intravenous corticosteroids are recommended. $76.9 \%(227 / 295)$ of the patients received systemic corticosteroids and 15.6\% (46/295) inhaled corticosteroids during hospitalization in Switzerland, as compared to $82.4 \%(12,960 / 15,723)$ of the patients receiving systemic corticosteroids and $34.3 \%(5,396 / 15,723)$ inhaling corticosteroids in the other European countries ( $p=0.015$ and $p<0.001$, respectively).

8 Antibiotic treatment is to be administered when a bacterial infection is suspected. In Switzerland, 72.5\% $(214 / 295)$ of the patients were treated with antibiotics during hospitalization. Amongst those patients who received antibiotics were 5 patients with sputum purulence and invasive mechanical ventilation (IMV) and 3 patients with no color change of the sputum,

Respiration 2017;94:355-365 361 
nonincreased sputum, and nonincreased dyspnea. In the other European countries, $86.2 \%(13,559 / 15,723)$ of the patients received antibiotic treatment $(p<$ $0.001)$.

9 Methylxanthines can be used as second-line therapy after short-acting bronchodilators. $1.0 \%$ (3/295) of the Swiss patients received methylxanthines; in the other European countries, $14.5 \%(2,273 / 15,723)$ of the patients were treated with this drug $(p=0.001)$.

10 NIV or IMV should be considered. 33.3\% (92/276) of the patients received noninvasive and 5.1\% (14/276) received IMV. 36 patients (12.2\%) in Switzerland fulfilled the British Thoracic Society guidelines for NIV $\left(\mathrm{pH}<7.35\right.$ and $\mathrm{pCO}_{2}>6 \mathrm{kPa}$ ) [14], and $66.7 \%$ of these patients received NIV, compared to $51.3 \%$ in the other European countries. 30\% (3/10) of the patients who fulfilled the GOLD IMV criteria $\left(\mathrm{pH}<7.25\right.$ and $\mathrm{pCO}_{2}$ $>8 \mathrm{kPa}$ ) [4] received IMV treatment, compared to $15.2 \%(70 / 461)$ in the rest of Europe.

\section{Outcomes}

The outcomes of the patients with severe AECOPD included in the audit in Switzerland and in the other European countries are presented in Table 4. In Switzerland, the patients had a prolonged hospital length of stay (on average 11.3 vs. 8.7 days; $p<0.001$ ), but a lower 90 -day readmission rate ( 25.4 vs. $35.3 \% ; p=0.003$ ). Although the overall mortality rate tended to be lower in Switzerland (8.1\%) than in the other European countries (10.9\%), Switzerland had a slightly higher rate of in-hospital deaths (5.4\%) than the other European countries (4.9\%).

\section{Discussion}

The European COPD Audit provided a unique overview of the management of exacerbations of COPD and their outcomes in Europe. The Swiss COPD Audit comprised 19 hospitals, thus representing the only available multicenter study in the country focusing specifically on the management of COPD exacerbations. Although the number of patients included was relatively modest and represented only $50 \%$ of the Swiss population, the Swiss COPD Audit offered objective data for the formation of action plans for exacerbation care in Switzerland.

A reliable diagnosis and accurate therapy are essential to improve patient outcomes after COPD exacerbation [4]. The diagnosis of COPD and the clinical diagnosis of exacerbation of COPD both benefit from spirometric in- formation. The absence of this information at admission may lead to incorrect diagnosis and treatment especially, since spirometry is not recommended during an acute exacerbation [4]. That said, $36 \%$ of the Swiss patients did not have any spirometry results available at admission, although the Swiss hospitals were better equipped than those of the other European countries.

Pulmonary rehabilitation improves the exercise capacity and quality of life of a patient [15]. Although pulmonary rehabilitation was available in $89.5 \%$ of all Swiss hospitals, only $40 \%$ of the patients took advantage of this therapeutic option. This could be attributed to the following: (1) pulmonary rehabilitation is not reimbursed by health insurance for any patients with mild disease; (2) pulmonary rehabilitation is offered as ambulatory treatment and many patients are too sick with too many comorbidities to be able to attend; and/or (3) physicians do not prescribe the rehabilitation program.

Evaluation of the severity of an exacerbation requires a blood gas analysis, particularly in those patients with hypoxemia as evidenced by transcutaneous oximetry [4]. It is especially striking that although a blood gas analysis is recommended in the GOLD guidelines [1], this examination was performed on only $85.6 \%$ of the patients fulfilling the criteria for severe exacerbation and thus requiring hospitalization. NIV reduces the mortality rate and the length of ICU and hospital stay [16]; yet only $66.7 \%$ of the patients fulfilling the ABG criteria for NIV received this therapy, and only $30.0 \%$ of those requiring IMV were treated accordingly. In the other European countries, NIV was administered to only $51.3 \%$ of the patients fulfilling the ABG criteria, and IMV to only $15.2 \%$ of the patients. NIV was, however, only available in $89.1 \%$ of the hospitals in the other European countries, and this could partly account for the lack of administration of this treatment in those countries. In Switzerland, NIV was available in all the participating hospitals.

Antibiotic use was significantly lower in the Swiss hospitals during hospitalization and after discharge, compared to the rest of Europe. The GOLD guidelines state that antibiotics should be administered when a bacterial infection is suspected [1]. With the increased usage of faster and more efficient molecular techniques, such as polymerase chain reaction, for detecting the type and presence of bacterial infections, as well as the use of circulating blood C-reactive protein (CRP) and procalcitonin (PCT) levels for determining the initiation of antibiotic administration, antibiotic usage can be decreased $[17,18]$. In view of the threat of an increase in antibiotic-
362

Respiration 2017;94:355-365

DOI: $10.1159 / 000477911$
Buess et al. 
resistant bacteria, less antibiotic usage during an exacerbation of COPD should be considered by the other European countries.

Administration of systemic corticosteroids before hospital admission was significantly higher in Switzerland than in the other European countries, but during hospitalization and after discharge, the Swiss patients were administered less systemic corticosteroids than the patients in the other European countries. The increased use of corticosteroids before admission may be due to the national model of care in Switzerland, where most patients referred for hospital admission have already been seen and have usually been treated by their general practitioner.

In accordance with the GOLD report 2010, fewer methylxanthines were used as a treatment option in Switzerland compared to the other European countries. Although more methylxanthines were used in the other European countries, the 90 -day readmission and follow-up mortality rates were significantly higher than in Switzerland. According to the GOLD recommendations, the beneficial effects of methylxanthines on lung function and other clinical end points are modest and inconsistent [1]. Recent data showing the effects of methylxanthines on inflammation and fibrosis may account for the increased use of methylxanthines in the other European countries [19-21].

More Swiss patients had consolidation than had patients from the other European countries. Saleh et al. [22] found that patients with COPD exacerbation who have consolidation have a more severe disease and worse prognosis than patients without consolidation. This could account for the longer hospital stay experienced by the Swiss patients compared to the patients from the other European countries.

There were significant differences in the prevalence of comorbidities between the Swiss patients and the patients from the other European countries. These differences may be due to differences in the complexity of workups in the various health-care systems across Europe. Since there are so many significant differences in treatment before and during hospitalization, it is difficult to determine which aspect of the treatment resulted in longer hospitalization, decreased readmission, and decreased follow-up mortality. It is also possible that these differences merely reflect different health-care models, as the length of hospital stay is not only determined by the severity of the disease but also by social and logistic factors facilitating home or institutional care.

Treatment of COPD Exacerbation in Switzerland
Swiss Recommendations for an Action Plan for

AECOPDs

Based on the available literature, collected data, and workshops involving respiratory physicians (hospital managers) representing all recruiting institutions, the following recommendations were established for the management of exacerbations of COPD in Switzerland. It is important to note that these recommendations may not be generalizable to all institutions in Switzerland.

1 Smoking cessation and vaccination information should be offered to COPD patients admitted to the hospital for exacerbation. Patients should be offered smoking cessation counselling and information regarding influenza and pneumococcal vaccination every time they are admitted to the hospital with an exacerbation. However, at the moment there is no reimbursement for non-physician smoking cessation counselling in the Swiss health care system, which may deter the introduction of this action [23]. We, therefore, additionally recommend including non-physician smoking cessation support in the Swiss tariff system and the fostering of a closer cooperation with the Swiss lung organization (Lungenliga).

2 ABG or venous blood gas should be measured. Patients' blood gas should be evaluated at presentation. The treatment and the diagnosis of exacerbation of COPD are very dependent on the blood gas analysis results; thus, for every patient with suspicion of severe exacerbation of COPD, we recommend that at least a venous blood gas analysis be performed $[24,25]$.

3 Medical staff should be trained in administering bronchodilators through a nebulizer with oxygen in the emergency ward. Patients should be offered oxygen at presentation. The cornerstone of treatment for AECOPD is bronchodilation with short-acting $\beta_{2}$-agonists at an increased dosis and frequency [4]. Medical staff should be trained in administering bronchodilators through a nebulizer with oxygen in the emergency ward to facilitate fast and correct therapy.

4 Systemic steroids should be administered. Patients should receive systemic steroids. Systemic steroids are efficient in the treatment of AECOPD, and they should be administered if there is a reasonable suspicion for an AECOPD. They reduce the recovery time of $\mathrm{FEV}_{1}$, hospital length of stay, and mortality rate [26]. The main effect of the steroids shows in the first $72 \mathrm{~h}$ of exacerbation. Based on the newest literature, we recommend a dose of 20-60 mg prednisone for 5 days [3, 27-29].

Respiration 2017;94:355-365

DOI: $10.1159 / 000477911$
363 
5 Antibiotics should be given to patients with increased sputum volume, purulent sputum, and increased CRP or PCT, and to patients requiring ICU admission. Patients should receive antibiotics only in selected cases. Antibiotic treatment is effective only in a small subgroup of patients with exacerbations. Indications for antibiotic administration include: increased sputum volume, sputum color, and purulence; need for ventilator support; or need for ICU transfer [30, 31]. In addition to the clinical condition of the patient, circulating CRP and PCT levels (e.g. $>50 \mathrm{mg} / \mathrm{dL}$ and $>0.25$ $\mu \mathrm{g} / \mathrm{L}$, respectively) should be evaluated to determine whether to initiate antibiotic treatment $[17,18]$.

$6 \mathrm{NIV}$ is indicated if $\mathrm{pH}<7.35$ and $\mathrm{pCO}_{2}>6 \mathrm{kPa}$. $\mathrm{Pa}-$ tients should receive ventilator support if $\mathrm{pH}<7.35$ and $\mathrm{pCO}_{2}>6 \mathrm{kPa}$. NIV should be administered as soon as possible when clinical and functional signs of acute respiratory distress are evident [32-36]. In this study, it was found that patients administered NIV had a survival probability of $80.4 \%$, compared to $64.4 \%$ of the patients treated with IMV [37]. NIV therapy outside the emergency ward or ICU is, however, challenging in Swiss hospitals, and these challenges will need to be addressed before this recommendation can be implemented.

7 Spirometry should be performed before discharging a patient or at least 4-6 weeks thereafter. Patients' lung function should be evaluated before discharge, or at least 4-6 weeks after discharge if this information is not available [36].
The European COPD Audit has some limitations, such as the lack of information on mucolytics and the vaccination status of the patients. Moreover, the recommended $\mathrm{FEV}_{1} / \mathrm{FVC}$ quotient for diagnosing COPD could overestimate the prevalence of the disease, particularly among elderly people.

In conclusion, considering the overall high standard of health care in Switzerland and in light of the GOLD 2010 guidelines, we were able to make 7 recommendations to improve and standardize the management of severe AECOPD for patients treated in Switzerland.

\section{Acknowledgments}

We would like to thank the European COPD Audit team for organizing and arranging the audit. We are thankful to all Swiss hospital managers for their great support in collecting the Swiss patient data and for fruitful discussions of the results to formulate the recommendations.

\section{Financial Disclosure and Conflicts of Interest}

The study was supported by the following institutions: the ERS, AstraZeneca, GlaxoSmithKline, Boehringer Ingelheim, Novartis, and Almirall. There was no conflict of interest. The financial support received was for expenses incurred in organizing workshops for the hospital managers.

\section{References}

1 WHO: Chronic obstructive pulmonary disease (COPD). 2016. http://www.who.int/ topics/chronic_obstructive_pulmonary_ disease/en/.

2 GBD 2015 Mortality and Causes of Death Collaborators: Global, regional, and national life expectancy, all-cause mortality and causespecific mortality for 249 causes of death, 1980-2015: a systematic analysis for the Global Burden of Disease Study 2015. Lancet 2016; 388:1459-1544.

3 Russi EW, Karrer W, Brutsche M, Eich C, Fitting JW, Frey M, Geiser T, Kuhn M, Nicod L, Quadri F, et al: Diagnosis and management of chronic obstructive pulmonary disease: the Swiss guidelines. Official guidelines of the Swiss Respiratory Society. Respiration 2013; 85:160-174.

4 Rodriguez-Roisin R: Global Strategy for the Diagnosis, Management and Prevention of COPD. 2010
5 Husebø GR, Bakke PS, Aanerud M, Hardie JA, Ueland T, Grønseth R, Persson LJ, Aukrust P, Eagan TM: Predictors of exacerbations in chronic obstructive pulmonary disease results from the Bergen COPD cohort study. PLoS One 2014;9:e109721.

6 Self TH, Patterson SJ, Headley AS, Finch CK: Action plans to reduce hospitalizations for chronic obstructive pulmonary disease exacerbations: focus on oral corticosteroids. Curr Med Res Opin 2014;30:2607-2615.

7 Connors AF Jr, Dawson NV, Thomas C, Harrell FE Jr, Desbiens N, Fulkerson WJ, Kussin P, Bellamy P, Goldman L, Knaus WA: Outcomes following acute exacerbation of severe chronic obstructive lung disease. The SUPPORT investigators (Study to Understand Prognoses and Preferences for Outcomes and Risks of Treatments). Am J Respir Crit Care Med 1996;154(pt 1):959-967.
8 Tokgoz Akyil F, Gunen H, Agca M, Gungor S, Yalcinsoy M, Sucu P, Akyil M, Sevim T: Patient outcome after chronic obstructive pulmonary disease exacerbations requiring noninvasive ventilation during hospitalization (in English, Spanish). Arch Bronconeumol 2016; 52:470-476.

9 Atsou K, Chouaid C, Hejblum G: Variability of the chronic obstructive pulmonary disease key epidemiological data in Europe: systematic review. BMC Med 2011;9:7.

10 Köhnlein T, Windisch W, Köhler D, Drabik A, Geiseler J, Hartl S, Karg O, LaierGroeneveld G, Nava S, Schönhofer B, et al: Non-invasive positive pressure ventilation for the treatment of severe stable chronic obstructive pulmonary disease: a prospective, multicentre, randomised, controlled clinical trial. Lancet Respir Med 2014;2:698-705.

11 Hartl S: The European COPD Audit: a pilot experience of 16 European countries. Pneumonol Alergol Pol 2012;80:501-504. 
12 López-Campos JL, Hartl S, Pozo-Rodríguez F, Roberts CM; European COPD Audit Team: European COPD Audit: design, organisation of work and methodology. Eur Respir J 2013; 41:270-276.

13 Roberts CM, López-Campos JL, Pozo-Rodríguez F, Hartl S; European COPD Audit Team: European hospital adherence to GOLD recommendations for chronic obstructive pulmonary disease (COPD) exacerbation admissions. Thorax 2013;68:1169-1171.

14 British Thoracic Society Standards of Care Committee: Non-invasive ventilation in acute respiratory failure. Thorax 2002;57:192-211.

15 Osthoff M, Leuppi JD: Management of chronic obstructive pulmonary disease patients after hospitalization for acute exacerbation. Respiration 2010;79:255-261.

16 Wedzicha JA, Miravitlles M, Hurst JR, Calverley PM, Albert RK, Anzueto A, Criner GJ, Papi A, Rabe KF, Rigau D, et al: Management of COPD exacerbations: a European Respiratory Society/American Thoracic Society guideline. Eur Respir J 2017;49:1600791.

17 Schuetz P, Briel M, Christ-Crain M, Stolz D, Bouadma L, Wolff M, Luyt CE, Chastre J, Tubach F, Kristoffersen KB, et al: Procalcitonin to guide initiation and duration of antibiotic treatment in acute respiratory infections: an individual patient data meta-analysis. Clin Infect Dis 2012;55:651-662.

18 Stolz D, Christ-Crain M, Bingisser R, Leuppi J, Miedinger D, Müller C, Huber P, Müller B, Tamm M: Antibiotic treatment of exacerbations of COPD: a randomized, controlled trial comparing procalcitonin-guidance with standard therapy. Chest 2007;131:9-19.

19 Ford PA, Durham AL, Russell RE, Gordon F, Adcock IM, Barnes PJ: Treatment effects of low-dose theophylline combined with an inhaled corticosteroid in COPD. Chest 2010; 137:1338-1344.

20 Zhang WH, Zhang Y, Cui YY, Rong WF, Cambier C, Devillier P, Bureau F, Advenier C, Gustin P: Can $\beta_{2}$-adrenoceptor agonists, anti- cholinergic drugs, and theophylline contribute to the control of pulmonary inflammation and emphysema in COPD? Fundam Clin Pharmacol 2012;26:118-134.

21 Yawn BP: Is “GOLD” standard for the management of COPD in clinical practice? Drugs Context 2012;2012:212243.

22 Saleh A, López-Campos JL, Hartl S, Pozo-Rodríguez F, Roberts CM; European COPD Audit Team: The effect of incidental consolidation on management and outcomes in COPD exacerbations: data from the European COPD Audit. PLoS One 2015;10:e134004.

23 Schuurmans WM, Bussinger C, Müller V, Burkhalter AK, Bolliger CT: Smoking cessation training for physicians and other health professionals in Switzerland (in German). Ther Umsch 2010;67:409-414.

24 Malatesha G, Singh NK, Bharija A, Rehani B, Goel A: Comparison of arterial and venous $\mathrm{pH}$, bicarbonate, $\mathrm{PCO}_{2}$ and $\mathrm{PO}_{2}$ initial emergency department assessment. Emerg Med J 2007;24:569-571.

25 Bloom BM, Grundlingh J, Bestwick JP, Harris $\mathrm{T}$ : The role of venous blood gas in the emergency department: a systematic review and meta-analysis. Eur J Emerg Med 2014;21:8188.

26 Woods JA, Wheeler JS, Finch CK, Pinner NA: Corticosteroids in the treatment of acute exacerbations of chronic obstructive pulmonary disease. Int J Chron Obstruct Pulmon Dis 2014;9:421-430.

27 Leuppi JD, Schuetz P, Bingisser R, Bodmer M, Briel M, Drescher T, Duerring U, Henzen C, Leibbrandt Y, Maier S, et al: Short-term vs conventional glucocorticoid therapy in acute exacerbations of chronic obstructive pulmonary disease: the REDUCE randomized clinical trial. JAMA 2013;309:2223-2231.

28 Walters JA, Tan DJ, White CJ, Gibson PG, Wood-Baker R, Walters EH: Systemic corticosteroids for acute exacerbations of chronic obstructive pulmonary disease. Cochrane Database Syst Rev 2014;9:CD001288.
29 Walters JA, Tan DJ, White CJ, Wood-Baker R: Different durations of corticosteroid therapy for exacerbations of chronic obstructive pulmonary disease. Cochrane Database Syst Rev 2014;12:CD006897.

30 Stefan MS, Rothberg MB, Shieh MS, Pekow PS, Lindenauer PK: Association between antibiotic treatment and outcomes in patients hospitalized with acute exacerbation of COPD treated with systemic steroids. Chest 2013;143:82-90.

31 Vollenweider DJ, Jarrett H, Steurer-Stey CA, Garcia-Aymerich J, Puhan MA: Antibiotics for exacerbations of chronic obstructive pulmonary disease. Cochrane Database Syst Rev 2012;12:CD010257.

32 Lindenauer PK, Stefan MS, Shieh MS, Pekow PS, Rothberg MB, Hill NS: Outcomes associated with invasive and noninvasive ventilation among patients hospitalized with exacerbations of chronic obstructive pulmonary disease. JAMA Intern Med 2014;174:1982-1993.

33 Olivieri C, Carenzo L, Vignazia GL, Campanini M, Pirisi M, Della Corte F, Navalesi P: Does noninvasive ventilation delivery in the ward provide early effective ventilation? Respir Care 2015;60:6-11.

34 Ramsay M, Hart N: Current opinions on noninvasive ventilation as a treatment for chronic obstructive pulmonary disease. Curr Opin Pulm Med 2013;19:626-630.

35 Boldrini R, Fasano L, Nava S: Noninvasive mechanical ventilation. Curr Opin Crit Care 2012;18:48-53.

36 Rea H, Kenealy T, Adair J, Robinson E, Sheridan N: Spirometry for patients in hospital and one month after admission with an acute exacerbation of COPD. Int J Chron Obstruct Pulmon Dis 2011;6:527-532.

37 Hartl S, López-Campos JL, Pozo-Rodríguez F, Castro-Acosta A, Studnicka M, Kaiser B, Roberts CM: Risk of death and readmission of hospital-admitted COPD exacerbations: European COPD Audit. Eur Respir J 2016;47: 113-121.
Treatment of COPD Exacerbation in Switzerland
Respiration 2017;94:355-365 DOI: $10.1159 / 000477911$ 